\title{
Screening Tests for Adults with Intellectual Disabilities
}

\author{
Joanne E. Wilkinson, MD, MSc, Larry Culpepper, MD, MPH, and Mary Cerreto, PhD
}

\begin{abstract}
Adults with intellectual disabilities need thoughtful, well-coordinated primary care from family physicians. However, evidence-based screening recommendations are lacking. We examined screening recommendations for common preventable conditions using the US Preventative Service Task Force guidelines. We also reviewed the literature about the prevalence of these conditions in adults with intellectual disabilities. Obesity, osteoporosis, and smoking are more prevalent in adults with intellectual disabilities, and enhanced screening for these conditions is recommended. Abnormal Papanicolaou smears and cervical cancer are less common in adults with intellectual disabilities and screening recommendations should be individualized. We also discussed strategies to make screening procedures less stressful for these patients. (J Am Board Fam Med 2007;20:399-407.)
\end{abstract}

The term "intellectual disabilities" (ID) refers to the condition of people with disabilities characterized by significant limitations both in cognitive functioning and adaptive behavior (conceptual, social, and practical adaptive skills) that originate before age 18 (Table 1). As used here, the term intellectual disabilities is synonymous with the term "mental retardation," a term that many people with ID dislike because it is stigmatizing and is frequently used as a global summary about complex human beings with a wide range of gifts, abilities, and needs. Challenges or limitations may be partially determined by the requirements of the environment in which people with ID live; the degree of disability may vary over time depending on the skills and supports the patient needs to function in his or her current environment. Adults with ID are living longer because of improved medical care,

This article was externally peer reviewed.

Submitted 5 December 2006; revised 18 March 2007; accepted 26 March 2007.

From the Department of Family Medicine, Boston University School of Medicine, Boston Medical Center, Boston, MA.

Funding: none.

Prior presentation: This work was presented in part at the Society for Teachers of Family Medicine Annual Meeting, Chicago, IL, on April 26, 2007.

Conflict of interest: none declared.

Corresponding author: Joanne E. Wilkinson, MD, MSc, Department of Family Medicine, Dowling 5, Boston University School of Medicine, 840 Harrison Avenue, Boston, MA 02118 (E-mail: joanne.wilkinson@bmc.org). technology, and environmental conditions. They are also more likely to live in community-based settings instead of large institutions. ${ }^{1}$ Adults with ID have expressed a preference to be treated by physicians like their nondisabled peers. ${ }^{2}$ However, despite recent summaries of health disparities and health risks for people with $\mathrm{ID}^{3}$ few guidelines exist in the literature to help practitioners make decisions about the health of their adult patients with ID, especially when screening for cardiovascular disease and cancer.

The screening guidelines of the US Preventive Services Task Force (USPSTF) have become the standard evidence-based source for preventive recommendations. To be appropriate for screening, a disease must (1) be serious and have important consequences; (2) be progressive, with early treatment more effective than later treatment; (3) possess a preclinical phase that can be easily identified by a screening test; and (4) have a preclinical phase with a relatively long duration that is prevalent in the screened population (see Table 2 ). ${ }^{4}$ For adults with ID, not all of these criteria are always met. For example, little is known about the prevalence of some diseases in people with ID in the United States; the data we have is often from other countries with a nationwide tracking system for people identified with ID in childhood. Further, barriers to screening may exist for some patients with ID, such as anxiety, lack of understanding of the test, transportation problems, and the need for extra 
Table 1. Diagnostic Criteria for Intellectual Disability (Formerly Mental Retardation)

1. Intellectual functioning significantly below the population mean (generally IQ score at least 2 standard deviations below the mean or $<75$ )

2. Significant limitation in adaptive skill areas (such that the patient cannot function adequately in their environment)on standardized testing, at least 2 standard deviations below the mean in one of these areas or on a combined score of all three:

Conceptual (receptive and expressive language, reading and writing, money concepts, self-direction)

Social (interpersonal, responsibility, self-esteem, gullibility, naivete, following rules, obeying laws, avoiding victimization)

Practical (eating, bathing, dressing, toileting, meal preparation, telephone use, taking medications, managing money, transportation, occupational skills, maintaining a safe environment)

3. Above limitations must be present and diagnosed before the age of eighteen

From the American Association of Intellectual and Developmental Disabilities (formerly American Association of Mental Retardation)

staff to accompany some patients from group homes to health care appointments. ${ }^{5}$

To date, few documents exist with recommendations for screening; one was published by the Massachusetts Department of Mental Retardation. ${ }^{6}$ These recommendations represent a consensus using standards from Massachusetts Health Quality Partners and a group of health professionals experienced in the care of adults with ID. However, there are no screening recommendations stemming directly from the evidence available in the medical literature. Here we attempt to review the USPSTF guidelines alongside the evidence available for people with ID and derive evidence- based guidelines for the screening of people with ID that can be used alongside the existing recommendations.

\section{Methods}

For this review, we searched Ovid/Medline using several terms in combination ("mental retardation" OR "intellectual disability" plus [the name of the condition] OR [the name of the screening test]) to generate initial lists of articles. These abstracts were reviewed and articles were excluded if they were not available in English, pertained only to children and not adults, were case studies, or were descriptions of scientific research unrelated to clinical medicine. The remaining articles were reviewed in more detail; those focusing on prevalence, screening, and diagnosis in the clinical setting were included in this review (Table 3). Two of the authors (MC, JW) conducted independent reviews to determine which articles were appropriate for inclusion in this article. Of 910 articles identified, 96 met the initial criteria for detailed review and 70 were used in this article.

Fourteen common screening tests were identified and the recommendations for their application were downloaded from the USPSTF Web site. ${ }^{7}$ For each test, the available literature was reviewed for people with ID to determine whether the screening recommendations should be any different for these patients (Table 4). Based on the quality and number of studies available pertaining to people with ID, the new recommendation was assigned a SORT rating (A, B, C, or I). When possible, special issues in screening unique to people with ID are discussed.

Table 2. Screening Criteria Applied to Adults with Intellectual Disabilities

Screening Criterion

Disease is serious and has important consequences.

Disease is progressive and early treatment is more effective than late treatment.

Disease progresses a preclinical phase easily identified by a screening test.

Preclinical phase is of long duration and is prevalent enough in screened population to limit false positives/ negatives.
Potential Difference in Population of Adults with Intellectual Disabilities

Same.

Depending on extent of cognitive impairment, treatment of disease might be logistically difficult or ineffective, if identified.

Adults with ID may have a longer detectable preclinical phase since limitations in cognitive functioning may preclude their accurately identifying and reporting symptoms.

Adults with ID may have different prevalence of certain diseases (ex. obesity, sexually transmitted diseases) compared with the general population.

Adapted from: Aschengrau and Seage, 2003. ${ }^{4}$ 


\begin{tabular}{|c|c|c|c|c|c|}
\hline $\begin{array}{l}\text { Search Terms ("Intellectual Disability" OR "Mental } \\
\text { Retardation" AND) }\end{array}$ & $\begin{array}{c}\text { Articles } \\
\text { Identified* (n) }^{*}\end{array}$ & $\begin{array}{l}\text { Basic Science or } \\
\text { Case Reports (n) }\end{array}$ & Other† & $\begin{array}{l}\text { Final Articles } \\
\text { Reviewed (n) }\end{array}$ & $\begin{array}{l}\text { Final Articles } \\
\text { Used (n) }\end{array}$ \\
\hline "Obesity" & 301 & 109 & 173 & 19 & 12 \\
\hline $\begin{array}{l}\text { "Cholesterol/ lipoproteins, LDL cholesterol/ } \\
\text { Lipoproteins, HDL cholesterol" }\end{array}$ & 79 & 69 & 6 & 4 & 3 \\
\hline "Diabetes Mellitus, Type 1/ Diabetes Mellitus, Type 2" & 28 & 16 & 11 & 1 & 0 \\
\hline "Hypertension" & 100 & 43 & 48 & 9 & 6 \\
\hline $\begin{array}{l}\text { "Smoking Cessation [Methods, Psychology, Statistics } \\
\text { and Numerical Data]" }\end{array}$ & 3 & 1 & 0 & 2 & 2 \\
\hline "Colonic Neoplasms" or "Colonoscopy" & 20 & 17 & 1 & 2 & 2 \\
\hline "Breast cancer" or "Mammogram" & 17 & 10 & 3 & 4 & 3 \\
\hline "Pap smear" or "Cervical Cancer" & 2 & 0 & 0 & 2 & 2 \\
\hline "Prostate Cancer" & 3 & 1 & 0 & 2 & 2 \\
\hline "Skin Neoplasms" & 33 & 25 & 8 & 0 & 0 \\
\hline “Osteoporosis" & 23 & 7 & 6 & 10 & 10 \\
\hline "Vision Screening" or "Vision" or "Vision Tests" & 57 & 2 & 33 & 14 & 12 \\
\hline "Hearing Disorders" or "Hearing Tests" & 116 & 23 & 86 & 7 & 5 \\
\hline "Mental Health" or "Depression" & 88 & 9 & 57 & 20 & 11 \\
\hline
\end{tabular}

* Via Ovid/Medline search and/or bibliographies of articles reviewed.

† Other reasons for elimination: pediatric subjects only, focused on a particular syndrome only (with the exception of Down syndrome), focused on treatment or intervention, not in English (or not translated), subject population included other types of cognitive impairment (such as dementia), or article did not address prevalence or screening.

\section{Results}

\section{Cardiovascular Screening}

Adults in general medical practices are routinely screened for obesity, hypertension, hypercholesterolemia, and diabetes and, depending on their risk factors, are counseled about smoking cessation (the USPSTF guidelines are summarized in Table 4). Adults with ID tend to be more sedentary than the general population ${ }^{8}$ and may have lower self-efficacy for behavior change, resulting in different rates of these conditions. ${ }^{9}$

The rates of overweight (body mass index 25.029.9) and obesity (body mass index >29.9) are higher in adults with ID, both in the United States ${ }^{10-14}$ and in other developed countries with lower overall rates of obesity. ${ }^{8,15-18}$ Adults with Down syndrome are particularly, although not exclusively, affected. ${ }^{19}$ In general, people with mild ID who lived in the community are most likely to be overweight or obese. ${ }^{14,16,20}$ Increased awareness and prevention of obesity in adults with ID is a major health goal. ${ }^{17,21,22}$ Weight measurement at least yearly and a discussion of diet and exercise for adult patients with ID is recommended, along with counseling appropriate to their individual strengths and supports $(S O R T=B)$.

Rates of hypercholesterolemia and dyslipidemia in adults with ID have not been reported as widely, but the existing data suggest that they are comparable to the general population. ${ }^{23}$ In people receiving atypical antipsychotics, cholesterol levels have been studied and found to be either slightly high$\mathrm{er}^{24}$ or the same $\mathrm{as}^{25}$ the rest of the intellectually disabled population. Further research is necessary on the impact of lifestyle, self-efficacy, and medications on cardiovascular risk factors in adults with ID. When screening for bypercholesterolemia, remember that adults with ID may have risk factors (such as obesity, inactivity, bypertension, smoking) that would necessitate screening at a younger age $(S O R T=C)$.

There are few data about diabetes in the population of adults with ID. Several articles discuss challenges in managing diabetes for patients with ID, especially those with Down syndrome or Prader-Willi syndrome. More recently, insulin resistance and metabolic syndrome in adults with ID have been studied, ${ }^{26}$ although prevalence was not specifically addressed. Until more is known about the rates of diabetes in the intellectually disabled adult population, our recommendation is to follow the USPSTF guidelines, remembering that patients with ID may have risk factors (see above) that would prompt earlier or more frequent screening $(S O R T=I)$.

The existing data on rates of hypertension in adults with ID is also somewhat conflicting. Adults 


\begin{tabular}{|c|c|c|c|c|}
\hline Screening & $\begin{array}{l}\text { USPSTF Guideline for All Adults in } \\
\text { the US }\end{array}$ & $\begin{array}{l}\text { USPTF } \\
\text { SOR }\end{array}$ & $\begin{array}{l}\text { Evidence-Based Recommendation for } \\
\text { Adults with ID }\end{array}$ & SORT \\
\hline $\begin{array}{l}\text { Obesity/body mass } \\
\text { index }\end{array}$ & $\begin{array}{l}\text { Yearly body mass index measurement } \\
\text { and counselling for obese patients }\end{array}$ & B & $\begin{array}{l}\text { At least yearly measurement; individualized } \\
\text { counselling }\end{array}$ & B \\
\hline Cholesterol/lipid & $\begin{array}{l}\text { Yearly screening for men over age } 35 \\
\text { and women over age } 45 \text { if average } \\
\text { risk (earlier if at risk) }\end{array}$ & A & $\begin{array}{l}\text { Be alert to higher incidence of risk factors } \\
\text { in this group* }\end{array}$ & $\mathrm{C}$ \\
\hline Diabetes & $\begin{array}{l}\text { Yearly glucose screening if } \\
\text { hypertensive or has } \\
\text { hyperlipidemia* }\end{array}$ & B & $\begin{array}{l}\text { Same as for cholesterol/lipid ; note } \\
\text { increased prevalence of risk }\end{array}$ & I \\
\hline Hypertension & $\begin{array}{l}\text { Yearly blood pressure measurement } \\
\text { for adults } \geq 18 \text { years of age }\end{array}$ & A & Same as for diabetes & $\mathrm{C}$ \\
\hline $\begin{array}{l}\text { Tobacco/smoking } \\
\text { cessation }\end{array}$ & $\begin{array}{l}\text { Regular counselling for all smokers } \\
\text { (at least yearly) }\end{array}$ & $\mathrm{A}$ & $\begin{array}{l}\text { Same as diabetes; individualized } \\
\text { counselling }\end{array}$ & I \\
\hline Colon cancer & $\begin{array}{l}\text { Fecal occult blood screening } \\
\quad \pm \text { scope yearly after age } 50\end{array}$ & A & $\begin{array}{l}\text { Same as diabetes; may combine with other } \\
\text { tests while patient is under sedation }\end{array}$ & B \\
\hline $\begin{array}{l}\text { Breast cancer } \\
\quad \text { (women) }\end{array}$ & $\begin{array}{l}\text { Mammogram every } 1-2 \text { years after } \\
\text { age } 39\end{array}$ & B & Same & $\mathrm{C}$ \\
\hline $\begin{array}{l}\text { Cervical cancer } \\
\text { (women) }\end{array}$ & Pap smear yearly if sexually active & A & $\begin{array}{l}\text { Pap individualized to patient's risk factors } \\
\text { (generally can be done less often) }\end{array}$ & B \\
\hline Prostate cancer & Insufficient evidence to recommend & I & Same as for cervical cancer & I \\
\hline Skin cancer & Insufficient evidence to recommend & I & $\begin{array}{l}\text { Same as for cervical cancer (probably less } \\
\text { prevalent) }\end{array}$ & I \\
\hline Osteoporosis & Bone densitometry & B & $\begin{array}{l}\text { Yearly screening beginning at age } 40 \text { for } \\
\text { institutionalized patients and age } 45 \text { for } \\
\text { community-dwelling patients }\end{array}$ & B \\
\hline Vision and hearing $\dagger$ & Yearly in all adults & & $\begin{array}{l}\text { At least yearly; modified/individualize } \\
\text { methods }\end{array}$ & B \\
\hline Mental health & $\begin{array}{l}\text { Regular screening for depression/ } \\
\text { mood disorders }\end{array}$ & B & $\begin{array}{l}\text { Yearly with attention to physical symptoms } \\
\text { of mood disorders }\end{array}$ & $\mathrm{C}$ \\
\hline
\end{tabular}

\footnotetext{
* Risk factors for CAD that would prompt earlier lipid measurement: hypertension, obesity, inactivity, family history of CAD, known diabetes or lipid disorder, cigarette smoking.

† Vision and hearing SOR is being updated based on availability of new research (2 to 28 to 07 ).

USPSTF, United States Preventive Services Task Force; SOR, strength of recommendation (as designated by the USPSTF for the general population); ID, intellectual disabilities; SORT = strength of recommendation taxonomy.
}

with ID may have more risk factors for the development of hypertension (obesity, inactivity, smoking), and one large study showed an inverse correlation of intelligence quotient in childhood with blood pressure later in life, although the subjects were not limited to people with ID. ${ }^{27}$ However, other studies noted lower rates of hypertension but similar death rates from cardiovascular disease in adults with ID compared with the general population. ${ }^{28-30}$ Still others commented on higher rates of hypertension as adults with ID age ${ }^{31}$ and noted that the overall risk profile for cardiovascular disease is worse in adults with ID. ${ }^{32}$ Until more research is available, following the USPSTF guidelines for hypertension screening is recommended $(S O R T=C)$.

\section{Smoking}

Smoking is a risk factor for both cardiovascular disease and lung cancer. Little data exists in the
United States on smoking rates among adults with ID. Lower smoking rates (compared with the general population) have been noted among adults with severe ID and equivalent or higher rates among community-dwellers and adults with mild ID. ${ }^{33}$ This may be because of the intellectually disabled adult modeling of their caregiver's smoking behavior ${ }^{34}$ or to limited success with smoking cessation. One study commented that people with ID were more likely to quit if encouraged to do so by their doctor. ${ }^{34}$ All patients with ID should be asked about smoking; the primary care physician should also provide smoking cessation counseling and treatment individualized to that person's cognitive strengths and limitations $(S O R T=I)$.

\section{Cancer Screening}

Cancer screening tests are recommended for adults in the general population, but logistic issues in- 
volved in testing may result in under-screening of adults with ID. It is biologically plausible that the risk for most types of cancer should be the same for people with and without ID.

In a large international study, ${ }^{35}$ colon cancer was found to be slightly more prevalent in adults with ID, although rates of adenomatous polyps in institutionalized adults with ID approximated the general population in a smaller study. ${ }^{36}$ Constipation is a common problem for adults with ID living in group homes, making the onset of colon cancer symptoms difficult to evaluate. We recommend following the USPSTF guidelines for colon cancer screening for adults with ID $(S O R T=B)$.

In a large retrospective cohort study, ${ }^{35}$ the incidence of breast cancer in women with ID was only slightly lower than that of the general population. Studies have commented on the associations between parity and breastfeeding ${ }^{37}$; women with ID are, in general, less likely to have children and to breastfeed, which may affect their risk. Researchers have commented on lower mammogram use in women with ID, ${ }^{38,39}$ noting the widespread lack of provider recommendation for the test. ${ }^{39}$ As women with ID live longer, primary care providers should make every effort to obtain a mammogram at regular intervals as recommended by the USPSTF $(S O R T=C)$.

Cervical cancer screening for women with ID is a topic of controversy. Fewer women with ID are sexually active compared with their non-intellectually disabled peers, putting them in a much lower risk group for cervical cancer. Two studies showed that when large samples of institutionalized women with ID were screened, the incidence of abnormal cervical cytology was extremely low. ${ }^{40,41}$ Community-dwelling women were not screened in these studies, and they are the most likely to be sexually active. Women with ID can also have difficulty communicating and might not be able to accurately relate their sexual history. There also may be other indications to do periodic gynecologic examinations (to evaluate for fibroids, ovarian masses, or dysmenorrheal). At this point, the available data argues against routine yearly Papanicolaou tests in women with ID. The decision to conduct Papanicolaou tests should be based more on the woman's sexual history than on her cognitive ability. Physicians should individualize the interval for cervical screening to the patient's risks $(S O R T=B)$.
Prostate cancer screening and skin cancer screening are performed regularly by many primary care providers despite insufficient evidence to recommend regular screening (as suggested by the USPSTF). There are also insufficient data to evaluate the incidence of skin cancer in the population of adults with ID, although 2 large studies document lower rates of prostate cancer in men with ID compared with the general population. ${ }^{35,42}$ The detectable preclinical phase for both cancers may be altered in people with ID because symptom detection and reporting are important in the early evaluation of these cancers. Physicians should screen their intellectually disabled adult patients as they would other adults in their patient panel until more data are available. Skin cancer prevention should be taught $(S O R T=I)$.

\section{Other Screening Tests}

Several investigators have documented the increased prevalence of osteoporosis in adults with ID, even among premenopausal women and men. ${ }^{43-47}$ A 2006 review focusing on women with ID highlighted risk factors, including inactivity, long-term anticonvulsant use, and possible Down syndrome. ${ }^{48}$ Multiple previous studies documented the high rates of osteopenia/osteoporosis in adults with ID and cited the same risk factors ${ }^{49,50}$ with the addition of low vitamin D levels. ${ }^{51}$ Given the high rates of osteoporosis documented among adults with ID, earlier screening is recommended beginning at younger ages (40 if living in an institution, 45 if communitydwelling; SORT = B).

Visual problems are more common in adults with ID than in their non-intellectually disabled peers in both domestic and international studies. $^{52-59}$ In addition, people with ID may be less likely to report visual symptoms or to have regular ophthalmic care. ${ }^{60-62}$ The method of screening may need to be individualized for patients with communication and perception limitations. ${ }^{63}$ Both vision and hearing problems can have a disproportionate impact on adults who rely on sensory input to compensate for some of their ID. Hearing problems have been found to be more prevalent in adults with ID compared with the general population, although all studies to date have been done in the Netherlands. ${ }^{64-68}$ These studies comment on the higher rates of hearing loss in older patients with ID and the contribution of cerumen impaction, an easily treated problem. Vision and hearing 
screenings should be performed regularly for adults with ID because the consequences of not screening are potentially significant $(S O R T=B)$.

The majority of studies focusing on mental health discuss the prevalence of "mental problems" rather than on specific conditions such as depression. Current research suggests somewhat higher rates of mood/affective disorders in adults with ID compared with the general population. ${ }^{69,70}$ Several studies have addressed the issue of how best to screen patients who may not be able to express their feelings effectively. ${ }^{71-73}$ There is an emerging consensus that, in adults with mild to moderate ID, self-report of symptoms is a reasonable way to screen, ${ }^{74}$ and there have been recent efforts to develop and validate screening tools for depression for adults with ID. ${ }^{75-77}$ Primary care physicians should screen for depression annually, looking for behaviors such as disturbances in sleep or eating, weight loss, and agitation and, when applicable, ask patients about symptoms of depression $(S O R T=C)$.

\section{Discussion}

There are sometimes additional logistic considerations when attempting to screen patients with ID. When being weighed and measured, some patients with moderate to severe ID can be anxious or frightened of the type of scale typically used in medical offices because the base can feel somewhat unsteady. These patients can be weighed at home on a regular bathroom scale and in a more familiar environment. For patients who are unstable when standing or have comorbid physical disabilities, the scale may need to be larger with more supports (multiple caregivers to help, a walker, or a grab bar). A note to call the day before the appointment can remind the caregiver to record a current weight at home before the visit.

Blood pressure can be handled in a similar manner. "White-coat hypertension" might be more prevalent in people with ID who are anxious about the medical office environment. Portable electronic blood pressure monitors are relatively inexpensive and can be used at any time. Home monitors allow the patient to have their blood pressure measured in a relaxed, familiar environment. Staff can sometimes work with patients to "desensitize" them to the sights and sounds of the medical office experience. Health care staff can take steps to seem less frightening to patients, for example, to avoid wearing white coats.
Blood draws can also be done at home under certain circumstances, and this technique may be preferable to a laboratory visit if the patient is very fearful. For cholesterol and glucose testing, it is sometimes acceptable to use fingerstick measurements if that is easier. Studies have shown that fingerstick measurement is acceptable for screening purposes, especially in low- to moderate-risk patients younger than $65 .^{78}$ However, fingerstick values can overestimate high-density lipoproteins and underestimate low-density lipoproteins, so treatment decisions should ideally be based on venous samples.

Vision screening often requires adaptive methods in patients with moderate to severe ID, and should be done by specialists if it cannot be done reliably by the primary care provider. An initial otoscopy to look for cerumen is recommended as the first step in hearing screening; patients can then have basic hearing tests either in the primary care office or with an audiologist, if needed.

For some adults with ID, sedation is required for routine procedures like dental work, endoscopic procedures, or minor surgery. If feasible, other tests the patient fears might be performed while the patient is sedated. For example, before or after dental work, vaccines could be administered, blood could be drawn, and gynecologic or other physical exams could be done. This practice requires coordination and communication among providers.

It should be noted that any decision about screening, whether it pertains to a patient with ID or a patient with typical intelligence, should be informed by the patient's comorbid medical conditions, life expectancy, and quality of life. These issues should be carefully considered in both populations with the caveat that many people with ID consider their quality of life to be good; the mere presence of ID should not be considered grounds to eschew screening.

\section{Implications for Research and Practice}

A major goal of Healthy People 2010 and Closing the Gap (the Surgeon General's "national blueprint to improve the health of persons with mental retardation") is the elimination of health disparities and improved delivery of primary care for people with disabilities. ${ }^{21,22}$ To provide appropriate care, physicians need updated, evidence-based recommendations specific to adults with ID. Adults with ID should be integrated into the fabric of society in 
general, and this includes "normalizing" their medical care as much as possible. However, without specific evidence-supported recommendations geared toward these patients, their care is in danger of being influenced by providers' assumptions about them, which may or may not be valid. More research is needed to gather data about adults with ID that can inform screening and other recommendations for their primary care. Most of the data informing the guidelines are from countries that may have rates of certain medical conditions that differ from those in the United States. It is important to collect data in the United States about the health status, exposures, and response to treatment for adults with ID so we can offer them evidencebased care. There is a real need for increased funding and research directed at this growing but neglected segment of our population.

\section{References}

1. Luckasson R, Coulter DL, Polloway EA, et al. Mental retardation: definition, classification and systems of support. Washington, DC: American Association of Mental Retardation; 2002.

2. Forts, A. What I want doctors to do for me that they are not doing now. In: Caring for individuals with Down syndrome and their families. Report of the 3rd Ross Roundtable on Critical Issues in Family Medicine in Collaboration with the Society for Teachers of Family Medicine. Columbus (OH): Ross Products Division, Abbott Laboratories; 1995.

3. Sullivan WF, Heng J, Cameron D, et al. Consensus guidelines for primary health care of adults with developmental disabilities. Can Fam Phys 2006;52: 1410-8.

4. Aschengrau A, Seage GM. Essentials of epidemiology in public health. Sudbury (MA): Jones and Bartlett Publishers; 2003.

5. Sullivan SG, Slack-Smith LM, Hussain R. Understanding the use of breast cancer screening services by women with intellectual disability. Soz Praventivmed 2004;49:398-405.

6. Massachusetts Department of Mental Retardation. Preventive health recommendations for adults with mental retardation (2002 May; revised 2003 September; cited 2007 February 27). Available from: www.mass.gov/Eeohhs2/docs/dmr/health_ screening_brochure.pdf.

7. US Department of Health and Human Services, Agency for Healthcare Research and Quality. US Preventive Services Task Force (cited 2007 February 27). Available from: www.ahrq.gov/clinic/ uspstfix.htm.

8. Emerson E. Underweight, obesity and exercise among adults with intellectual disabilities in sup- ported accommodation in Northern England. J Intell Disabil Res 2005;49(Pt 2):134-43.

9. Robertson J, Emerson E, Gregory N, et al. Lifestyle related risk factors for poor health in residential settings for people with intellectual disabilities. Res Dev Disabil 2000;21:469-86.

10. Rimmer JH, Yamaki K. Obesity and intellectual disability. Ment Retard Dev Disabil Res Rev 2006;12: 22-7.

11. Draheim CC. Cardiovascular disease prevalence and risk factors of persons with mental retardation. Ment Retard Dev Disabil Res Rev 2006;12:3-12.

12. Moran R, Drane W, McDermott S, Dasari S, Scurry JB, Platt T. Obesity among people with and without mental retardation across adulthood. Obes Res 2005; 13:342-9.

13. Yamaki K. Body weight among adults with intellectual disability in the community. Ment Retard 2005; 43:1-10.

14. Rimmer JH, Braddock D, Fujiura G. Prevalence of obesity in adults with mental retardation: implications for health promotion and disease prevention. Ment Retard 1993;31:105-10.

15. Bertoli S, Battezzati A, Merati G, et al. Nutritional status and dietary patterns in disabled people. Nutr Metab Cardiovasc Dis 2006;16:100-12. Epub 2005 Nov 10.

16. Hove O. Weight survey on adult persons with mental retardation living in the community. Res Dev Disabil 2004;25:9-17.

17. Turner S, Moss S. The health needs of adults with learning disabilities and the Health of the Nation strategy. J Intell Disabil Res 1996;40(Pt 5):438-50.

18. Simila S, Niskanen P. Underweight and overweight cases among the mentally retarded. J Ment Deficiency Res 1991;35(Pt 2):160-4.

19. Bell AJ, Bhate MS. Prevalence of overweight and obesity in Down's syndrome and other mentally handicapped adults living in the community. J Intell Disabil Res 1992;36(Pt 4):359-64.

20. Frey B, Rimmer JH. Comparison of body composition between German and American adults with mental retardation. Med Sci Sports Exer 1995;27: $1439-43$.

21. US Department of Health and Human Services, Office of Disease Prevention and Health Promotion. Healthy People 2010 (cited 2007 February 27). Available from: www.healthypeople.gov.

22. Office of the Surgeon General. Health Disparities and Mental Retardation. Closing the gap: a national blueprint to improve the health of persons with mental retardation (updated 2004 April 27; cited 2007 February 27). Available from: www.surgeongeneral. gov/topics/mentalretardation/.

23. Rimmer JH, Braddock D, Fujiura G. Cardiovascular risk factor levels in adults with mental retardation. Am J Ment Retard 1994;98:510-8.

24. McKee JR, Bodfish JW, Mahorney SL, Heeth WL, 
Ball MP. Metabolic effects associated with atypical antipsychotic treatment in the developmentally disabled. J Clin Psychiatry 2005;66:1161-8.

25. Cohen S, Fitzgerald B, Okos A. Khan S, Khan A. Weight, lipids, glucose, and behavioral measures with ziprasidone treatment in a population with mental retardation. J Clin Psychiatry 2003;64:60-2.

26. Draheim CC, Williams DP, McCubbin JA. Physical activity, dietary intake, and the insulin resistance syndrome in nondiabetic adults with mental retardation. Am J Ment Retard 2002;107:361-75.

27. Starr JM, Taylor MD, Hart CL, et al. Childhood mental ability and blood pressure at midlife: linking the Scottish Mental Survey 1932 and the Midspan studies. J Hypertension 2004;22:893-7.

28. Draheim CC, McCubbin JA, Williams DP. Differences in cardiovascular disease risk between nondiabetic adults with mental retardation with and without Down syndrome. Am J Ment Retard 2002;107: 201-11.

29. McDermott S, Platt T. Are individuals with mental retardation at high risk for chronic diseases? Fam Med 1997;29:429-34.

30. Janicki MP, Davidson PW, Henderson CM, et al. Health characteristics and health services utilization in older adults with intellectual disability living in community residences. J Intell Disabil Res 2002; 46(Pt 4):287-98.

31. Cooper SA. Clinical study of the effects of age on the physical health of adults with mental retardation. Am J Ment Retard 1998;102:582-9.

32. Beange H, McElduff A, Baker W. Medical disorders of adults with mental retardation: a population study. Am J Ment Retard 1995;99:595-604.

33. McGillicuddy NB. A review of substance use research among those with mental retardation. Ment Retard Dev Disabil Res Rev 2006;12:41-7.

34. Minihan PM. Smoking policies and practices in a state-supported residential system for people with mental retardation. Am J Ment Retard 1999;104: 131-142.

35. Sullivan SG, Hussain R, Threlfall T, Bittles AH. The incidence of cancer in people with intellectual disabilities. Cancer Cause Control 2004;15:1021-5.

36. Uno Y. Mental retardation and colorectal disease: colonoscopic mass screening to determine whether the risk of adenomatous polyposis screening is increased in the mentally retarded. J Gastroenterol Hepatol 1996;11:275-8.

37. Maskarinec G, Zhang Y, Pagano I, et al. Trends of breast cancer incidence and risk factor prevalence over 25 years. Breast Cancer Res Treat 2006;98:4555.

38. Sullivan SG, Glasson EJ, Hussain R, et al. Breast cancer and the uptake of mammography screening services by women with intellectual disabilities. Prev Med 2003;37:507-12.

39. Davies N, Duff M. Breast cancer screening for older women with intellectual disability living in community group homes. J Intellect Disabil Res 2001;45(Pt 3):253-7.

40. Quint E, Elkins T. Cervical cytology in women with mental retardation. Obstet Gynecol 1997;89:123-6.

41. Jaffe JS, Timell AM, Eisenberg MS, Chambers JT. Low prevalence of abnormal cervical cytology in an institutionalized population with intellectual disability. J Intell Disabil Res 2002;46(Pt 7):569-74.

42. Patja K, Eero P, Iivanainen M. Cancer incidence among people with intellectual disability. J Intell Disabil Res 2001;45(Pt 4):300-7.

43. Angelopoulu N, Matziari C, Tsimaras V, Sakadamis A, Souftas V, Mandroukas K. Bone mineral density and muscle strength in young men with mental retardation (with and without Down Syndome). Calcif Tissue Int 2000;66:176-80.

44. Jaffe JS, Timell AM. Prevalence of low bone density in institutionalized men with intellectual disabilities. J Clin Densitom 2003;6:143-7.

45. Tyler CV, Snyder CW, Zyzanski S. Screening for osteoporosis in community-dwelling adults with mental retardation. Ment Retard 2000;38:316-21.

46. Center J, Beange H, McElduff A. People with mental retardation have an increased prevalence of osteoporosis: a population study. Am J Ment Retard 1998;103:19-28.

47. Aspray TJ, Francis RM, Thompson A, Quilliam SJ, Rawlings DJ, Tyrer SP. Comparison of ultrasound measurements at the heel between adults with mental retardation and control subjects. Bone 1998;22: 665-8.

48. Schrager S. Epidemiology of osteoporosis in women with cognitive impairment. Ment Retard 2006;44: 203-11.

49. Jaffe JS, Timell AM, Elolia R, Thatcher SS. Risk factors for low bone mineral density in individuals residing in a facility for the people with intellectual disability. J Intell Disabil Res 2005;49(Pt 6):457-62.

50. Lohiya GS, Tan-Figueroa L, Iannucci A. Identification of low bone mass in a developmental center: finger bone mineral density measurement in 562 residents. J Am Med Dir Assoc 2004;5:371-6.

51. Wagemans AM, Fiolet JF, van der Linden ES, Menheere PP. Osteoporosis and intellectual disability: Is there any relation? J Intell Disabil Res 1998;42(Pt 5):370 - 4 .

52. van den Broek EG, Janssen CG, van Ramshorst T, Deen L. Visual impairments in people with severe and profound multiple disabilities: an inventory of visual functioning. J Intell Disabil Res 2006;50(Pt 6):470-5.

53. Isralowitz R, Madar M, Reznik A. Vision needs of people with intellectual disability in residential facilities and community-based homes for independent living. Disabil Rehabil 2005;27:1451-3.

54. Woodhouse JM, Adler P, Duignan A. Vision in athletes with intellectual disabilities: the need for im- 
proved eyecare. J Intell Disabil Res 2004;48(Pt 8): 736-45.

55. VanSplunder J, Stilma JS, Bernsen RM, Evenhuis HM. Prevalence of ocular diagnoses found on screening 1539 adults with intellectual disabilities. Ophthalmology 2004;111:1457-63.

56. Warburg M. Visual impairment in adult people with moderate, severe, and profound intellectual disability. Acta Ophthalm Scandin 2001;79:450-4.

57. McCulloch DL, Sludden PA, McKeown K, Kerr A. Vision care requirements among intellectually disabled adults: a residence-based pilot study. J Intell Disabil Res 1996;40(Pt 2):140-50.

58. Haire AR, Vernon SA, Rubinstein MP. Levels of visual impairment in a day centre for people with a mental handicap. J Royal Soc Med 1991;84:542-4.

59. Sacks JG, Goren MB, Burke MJ, White SS. Ophthalmologic screening of adults with mental retardation. Am J Ment Retard 1991;95:571-4.

60. Isralowitz R, Madar M, Lifshitz T, Assa V. Visual problems among people with mental retardation. Int J Rehab Res 2003;26:149-52.

61. Warburg M. Visual impairment in adult people with intellectual disability: literature review. J Intell Disabil Res 2001;45(Pt 5):424-38.

62. Block SS, Beckerman SA. Berman PE. Vision profile of the athletes of the 1995 Special Olympics World Summer Games. J Am Optom Assoc 1997;68:699708.

63. O'Dell CD, Harshaw K, Boothe RG. Vision screening of individuals with severe or profound mental retardation. Ment Retard 1993;31:154-60.

64. Meuwese-Jongejeugd A, Vink M, van Zanten B, et al. Prevalence of hearing loss in 1598 adults with an intellectual disability: cross-sectional populationbased study. Int J Audiol 2006;45:660-9.

65. Evenhuis HM, Mul M, Lemaire EK, de Wijs JP. Diagnosis of sensory impairment in people with intellectual disability in general practice. J Intell Disabil Res 1997;41(Pt 5):422-9.

66. Evenhuis HM, Theunissen M, Denkers I, Verschuure H, Kemme H. Prevalence of visual and hearing impairment in a Dutch institutionalized population with intellectual disability. J Intell Disabil Res 2001;45(Pt 5):457-64.

67. Evenhuis HM. Medical aspects of ageing in a pop- ulation with intellectual disability II: Hearing impairment. J Intell Disabil Res 1995;39(Pt 1):27-33.

68. Van Schrojenstein Lantman-de Valk HM, Haveman MJ, Maaskant MA, Kessels AG, Urlings HF, Sturmans F. The need for assessmet of sensory functioning in ageing people with mental handicap. J Intell Disabil Res 1994;38(Pt 3):289-98.

69. Cooper SA, Smiley E, Morrison J, Williamson A, Allan L. An epidemiological investigation of affective disorders with a population-based cohort of 1023 adults with intellectual disabilities. Psychol Med 2007 Feb 5:1-10. Epub 2007 Feb 5.

70. Cooper SA, Smiley E, Morrison J, Williamson A, Allan L. Mental ill-health in adults with intellectual disabilities: prevalence and associated factors. Br J Psychol 2007;190:27-35.

71. Ross E, Oliver C. The assessment of mood in adults who have severe or profound mental retardation. Clin Psychol Rev 2003;23:225-45.

72. Ross E, Oliver C. The relationship between levels of mood, interest and pleasure and 'challenging behaviour' in adults with severe and profound intellectual disability. J Intell Disabil Res 2002;46(pt 3):191-7.

73. Bramston P, Fogarty G. The assessment of emotional distress experienced by people with an intellectual disability: a study of different methodologies. Res Dev Disabil 2000;21:487-500.

74. McBrien JA. Assessment and diagnosis of depression in people with intellectual disability. J Intell Disabil Res 2003;47(Pt 1):1-13.

75. Esbensen AJ, Seltzer MM, Greenberg JS, Benson BA. Psychometric evaluation of a self-report measure of depression for individuals with mental retardation. Am J Ment Retard 2005;110:469-81.

76. Esbensen AJ, Benson BA. Cognitive variables and depressed mood in adults with intellectual disability. J Intell Disabil Res 2005;49(Pt 7):481-9.

77. Esbensen AJ, Rojahn J, Aman MG, Ruedrich S. Reliability and validity of an assessment instrument for anxiety, depression, and mood among individuals with mental retardation. J Autism Dev Disord 2003; 33:617-29.

78. Stein JH, Carlsson CM, Papcke-Benson K, Einerson JA, McBride PE, Wiebe DA. Inaccuracy of lipid measurements with the portable Cholestech LDX analyzer in patients with hypercholesterolemia. Clin Chem 2002;48:284-90. 